Research

Open Access

\title{
Late initiation of renal replacement therapy is associated with worse outcomes in acute kidney injury after major abdominal
}

\section{surgery}

Chih-Chung Shiao ${ }^{1}$, Vin-Cent $\mathrm{Wu}^{2}$, Wen-Yi Li ${ }^{3}$, Yu-Feng Lin², Fu-Chang Hü4, Guang-Huar Young ${ }^{5}$, Chin-Chi Kuo ${ }^{3}$, Tze-Wah Kao'2, Down-Ming Huang ${ }^{3}$, Yung-Ming Chen'2, Pi-Ru Tsai5, ShueiLiong Lin², Nai-Kuan Chou ${ }^{5}$, Tzu-Hsin Lin ${ }^{5}$, Yu-Chang Yeh ${ }^{6}$, Chih-Hsien Wang ${ }^{5}$, Anne Chou ${ }^{6}$, Wen-Je Ko ${ }^{5}$, Kwan-Dun $\mathrm{Wu}^{2}$ for the National Taiwan University Surgical Intensive Care UnitAssociated Renal Failure (NSARF) Study Group

\author{
1Division of Nephrology, Department of Internal Medicine, Saint Mary's Hospital, 160 Chong-Cheng South Road, Lotung 265, I-Lan, Taiwan \\ 2Division of Nephrology, Department of Internal Medicine, National Taiwan University Hospital, 7 Chung-Shan South Road, Taipei 100, Taiwan \\ ${ }^{3}$ Division of Nephrology, Department of Internal Medicine, National Taiwan University Hospital Yun-Lin Branch, No.579, Sec. 2, Yunlin Rd., Douliu \\ City, Yunlin County 640, Taiwan \\ ${ }^{4}$ National Center of Excellence for General Clinical Trial and Research, National Taiwan University Hospital, 7 Chung-Shan South Road, Taipei 100, \\ Taiwan \\ 5Department of Surgery, National Taiwan University Hospital, 7 Chung-Shan South Road, Taipei 100, Taiwan \\ ${ }^{6}$ Department of Anesthesiology, National Taiwan University Hospital, 7 Chung-Shan South Road, Taipei 100, Taiwan \\ Corresponding author: Wen-Je Ko, kowj@ntu.edu.tw \\ Received: 7 Aug 2009 Revisions requested: 24 Aug 2009 Revisions received: 28 Sep 2009 Accepted: 30 Oct 2009 Published: 30 Oct 2009 \\ Critical Care 2009, 13:R171 (doi:10.1186/cc8147) \\ This article is online at: http://ccforum.com/content/13/5/R171 \\ (c) 2009 Shiao et al.; licensee BioMed Central Ltd. \\ This is an open access article distributed under the terms of the Creative Commons Attribution License (http://creativecommons.org/licenses/by/2.0), \\ which permits unrestricted use, distribution, and reproduction in any medium, provided the original work is properly cited.
}

\begin{abstract}
Introduction Abdominal surgery is probably associated with more likelihood to cause acute kidney injury (AKI). The aim of this study was to evaluate whether early or late start of renal replacement therapy (RRT) defined by simplified RIFLE (sRIFLE) classification in AKI patients after major abdominal surgery will affect outcome.

Methods A multicenter prospective observational study based on the NSARF (National Taiwan University Surgical ICU Associated Renal Failure) Study Group database. 98 patients (41 female, mean age $66.4 \pm 13.9$ years) who underwent acute RRT according to local indications for post-major abdominal surgery AKI between 1 January, 2002 and 31 December, 2005 were enrolled The demographic data, comorbid diseases, types of surgery and RRT, as well as the indications for RRT were documented. The patients were divided into early dialysis
\end{abstract}

(sRIFLE-0 or Risk) and late dialysis (LD, sRIFLE -Injury or Failure) groups. Then we measured and recorded patients' outcome including in-hospital mortality and RRT wean-off until 30 June, 2006.

Results The in-hospital mortality was compared as endpoint. Fifty-seven patients $(58.2 \%)$ died during hospitalization. LD (hazard ratio (HR) 1.846; $P=0.027$ ), old age (HR 2.090; $P=$ 0.010 ), cardiac failure (HR 4.620; $P<0.001$ ), pre-RRT SOFA score (HR 1.152; $P<0.001$ ) were independent indicators for in-hospital mortality.

Conclusions The findings of this study support earlier initiation of acute RRT, and also underscore the importance of predicting prognoses of major abdominal surgical patients with AKI by using RIFLE classification.

AKI: acute kidney injury; APACHE II: Acute Physiology and Chronic Health Evaluation II; BUN: blood urea nitrogen; Cl: confidence interval; CKD: chronic kidney disease; CVP: central venous pressure; ED: early dialysis; GCS: Glascow Coma Scale; GFR: glomerular filtration rate; GI: gastrointestinal; HR: hazard ratio; ICU: intensive care unit; LD: late dialysis; MDRD: Modification of Diet in Renal Disease; RR: relative risk; RRT: renal replacement therapy; sCr: serum creatinine; sK+'serum K; SOFA: Sequential Organ Failure Assessment. 


\section{Introduction}

Acute kidney injury (AKI) is a common problem in critically ill patients, with a reported incidence of 1 to $25 \%$ and a poor prognosis $[1,2]$. Postoperative AKI is one of the most serious complications in surgical patients [3]. The risk factors of postoperative AKI include emergent surgery [4], exposure to nephrotoxic drugs, hypotension, hypovolemia, hypothermia, inflammatory response to surgery [5,6], and cardiac dysfunction [3]. On the other hand, hospital-acquired infection also contributes to the development of $\mathrm{AKI}$ in patients who receive emergent abdominal surgery. The abdominal compartment syndrome, which develops after sustained and uncontrolled intra-abdominal hypertension and may result in AKI or mortality, is being increasingly observed in the general surgical population [7]. Thus it was assumed that abdominal surgery is probably associated with an increased likelihood of developing $\mathrm{AKI}$.

The appropriate timing of renal replacement therapy (RRT) initiation in patients with AKI has been under debate for a long time. From the view point of an early renal support strategy, the goal of early RRT is to maintain solute clearance and fluid balance to prevent subsequent multi-organ damage, while waiting for the recovery of renal function [8]. Although a metaanalysis by Seabra and colleagues [9] revealed a beneficial effect of early initiation of RRT, the benefits of early acute dialysis remain controversial [10-12]. The aim of the present study was to evaluate whether the timing of RRT affected the in-hospital mortality rate in patients with AKI after major abdominal surgery.

\section{Materials and methods Study populations}

This study was based on the National Taiwan University Surgical ICU Associated Renal Failure (NSARF) Study Group database. The database was constructed for quality and outcome assurance in one medical center (National Taiwan University Hospital, Taipei, Northern Taiwan) and its three branch hospitals in different cities. Since 2002, the database recruited all patients requiring RRT during their intensive care unit (ICU) stay, and prospectively collected data in these four hospitals [13-15]. From January 2002 to December 2005, adult patients who underwent major abdominal surgery with postoperative AKI requiring RRT in ICU were enrolled into this multicenter prospective observational study. Exclusion criteria included patients aged less than 18 years, patients with an ICU stay of less than two days, patients who started dialysis before surgery, patients who didn't undergo abdominal surgery, or patients who underwent renal transplantation. Those enrolled were treated by the same team of physicians and nurses, and followed until 30 June, 2006. Surgical procedures were considered major if the length of hospital stay for patients in a given diagnosis-related group exceeded two days [1518]. Informed consent was waived because there was no breach of privacy and it did not interfere with clinical decisions related to patient care. Approval for this study was obtained from the Institutional Review Board of National Taiwan University Hospital (No. 31MD03).

\section{Patient information and data collection}

The demographic data, comorbid diseases, types of surgery and RRT, as well as the indications for RRT were documented. The biochemistry data such as complete blood cell count, blood urea nitrogen (BUN), serum creatinine ( $\mathrm{sCr}$ ), glomerular filtration rate (GFR), serum albumin, and serum potassium $\left(\mathrm{sK}^{+}\right)$were recorded upon ICU admission and RRT initiation. Severity scores including Glascow Coma Scale (GCS) score, Acute Physiology and Chronic Health Evaluation II (APACHE II) [19] score, and Sequential Organ Failure Assessment (SOFA) [20] score were also measured at the two time points. Also, the need for mechanical ventilation was recorded and the usage of inotropic equivalent was calculated to evaluate the vasopressor dose [21]. Then we measured and recorded patients' outcome including in-hospital mortality and RRT wean-off.

Definitions were made as following: diabetes, previous usage of insulin or oral hypoglycemic agents; hypertension, blood pressure above 140/90 $\mathrm{mmHg}$ or usage of anti-hypertension agents; cardiac failure, low cardiac output with a central venous pressure (CVP) above $12 \mathrm{mmHg}$ and an dopamine equivalent above $5 \mu \mathrm{g} / \mathrm{kg} / \mathrm{min}$ [21]; chronic kidney disease (CKD), sCr of $1.5 \mathrm{mg} / \mathrm{dl}$ or greater documented prior to this admission [22]; sepsis, persisted or progressive signs and symptoms of the systemic inflammatory response syndrome with a documented or presumed persistence of infection [23]; RRT wean-off, cessation from RRT for at least 30 days [15].

The types of major abdominal surgery were further divided into five categories depending on the involvement of abdominal organs: (1) hepatobiliary organ, (2) upper gastrointestinal (GI) tract, (3) lower Gl tract, (4) urological organs, and (5) other sites. 'Upper Gl tract' was defined as the duodenum and above, while 'lower Gl tract' included the area from the jejunum to rectum. If the surgery didn't involve the one of the four major organs ( 1 to 4 ), it would be categorized as 'other sites' (5).

The modality of RRT was chosen according to the hemodynamics of the patients. Continuous venovenous hemofiltration was performed, if more than 15 points of inotropic equivalent [15] was required to maintain systemic blood pressure up to $120 \mathrm{mmHg}$, using high-flux filters (Hemofilter, PAN-10, Asahi Kasei, Japan) and HF 400 (Informed, Geneva, Switzerland). The hemofiltration flow and blood flow blood flow were $35 \mathrm{ml} /$ $\mathrm{kg} /$ hour and $200 \mathrm{ml} / \mathrm{min}$, respectively. Replacement fluid was bicarbonate-buffered and was administered predilutionally at a dynamically adjusted rate to achieve the desired fluid therapy goals. Default composition was sodium $142 \mathrm{mEq} / \mathrm{l}$, bicarbonate $33 \mathrm{mEq} / \mathrm{l}$, calcium $2.6 \mathrm{mEq} / \mathrm{l}$, and magnesium $1.4 \mathrm{mEq} / \mathrm{l}$. Intermittent hemodialysis was performed for four hours except 
for the first and second sessions with a dialysate flow of 500 $\mathrm{ml} / \mathrm{min}$ and blood flow of $200 \mathrm{ml} / \mathrm{min}$ [18], using low-flux polysulfone hemofilters (KF-18C, Kawasumi Laboratories, Shinagawa-ku, Tokyo, Japan). Double lumen catheters were placed as vascular access.

In the ICUs, the indications for RRT initiation were: (1) azotemia (BUN $>80 \mathrm{mg} / \mathrm{dL}$ and $\mathrm{sCr}>2 \mathrm{mg} / \mathrm{dl}$ ) with uremic symptoms (encephalopathy, nausea, vomiting, etc); (2) oliguria (urine amount $<200 \mathrm{ml} / 8$ hours) or anuria refractory to diuretics; (3) fluid overload refractory to diuretics use with a CVP level above $12 \mathrm{mmHg}$ or pulmonary edema with a partial pressure of arterial oxygen/fraction of inspired oxygen ratio below $300 \mathrm{mmHg}$; (4) hyperkalemia ( $\mathrm{sK}^{+}>5.5 \mathrm{mmol} / \mathrm{L}$ ) refractory to medical treatment; and (5) metabolic acidosis $(\mathrm{a} \mathrm{pH}<7.2$ in arterial blood gas) $[13,18]$. We recorded all the indications of patients upon RRT initiation.

\section{Covariate}

Patients were categorized into two groups (early dialysis (ED) and late dialysis (LD)) according to their RIFLE (Risk, Injury, Failure, Loss, and End stage) classification [24] (Table 1) before RRT initiation. The RIFLE classification was first proposed by the Acute Dialysis Quality Initiative group in an attempt to standardize AKI study, and the scores could be used to predict the mortality after major surgery $[25,26]$. There were many studies comparing the prognoses among patients in different categories of RIFLE classification, but only a few studies $[27,28]$ compared the outcome among patients who initiated RRT in different categories of RIFLE classification. As in previous studies $[27,29,30]$, we used 'simplified' RIFLE (sRIFLE) classification with only GFR criterion applied for classification because the eight-hourly urine volumes in our database could not match the 6- or 12-hourly urine output criterion in RIFLE classification. Those who initiated RRT when in sRIFLE-R (risk) or sRIFLE-0 [26], which means not yet reaching the sRIFLE-R level were defined as 'ED', while in SRIFLE-I (injury) or sRIFLE-F (failure) were classified as 'LD'. The baseline $\mathrm{sCr}$ was the data obtained at hospital discharge from the previous admission in those who had more than one admission [29], or the data estimated using the Modification of Diet in
Renal Disease (MDRD) equation [31] in those with only one admission (assuming an average GFR of $75 \mathrm{ml} / \mathrm{min} / 1.73 \mathrm{~m}^{2}$ ). The peak sCr was defined as the highest $\mathrm{sCr}$ before RRT initiation in ICUs. The GFR were estimated using the isotope dilution mass spectrometry--traceable four-variable MDRD equation [31].

\section{Outcomes}

The endpoint of this study was in-hospital mortality. The survival period was calculated from RRT initiation to mortality (in non-survivors) or hospital discharge (in survivors).

\section{Statistical analysis}

Statistical analyses were performed with the Scientific Package for Social Science for Windows (SPSS, version 13.0, SPSS Inc, Chicago, IL, USA). Continuous data were expressed as mean \pm standard deviation unless otherwise specified. Percentage was calculated for categorical variables. Student's $t$ test was used to compare the means of continuous data, whereas Chi-squared test or Fisher's exact test was used to analyze categorical proportions. Then we used backward stepwise likelihood ratio model of Cox proportional hazard method to analyze the independent predictors for inhospital mortality. The independent variables were selected for multivariate analysis if they had a $P \leq 0.1$ on univariate analysis. The basic model-fitting techniques for (1) variable selection, (2) goodness-of-fit assessment, and (3) regression diagnostics (e.g., residual analysis, detection of influential cases, and check for multicollinearity) were used in our regression analyses to ensure the quality of analysis results. Specifically, we used the stepwise variable selection procedure with both significance level for entry and significance level for stay set to 0.15 or larger to select the relevant covariates into the final Cox proportional hazards model. Also, we did an additional analysis adjusting for three clinical relevant variables (namely, sepsis before RRT, mechanical ventilation, and diabetes) regardless of $P$ value because they were considered important. Furthermore, we did the analysis comparing sRIFLE categories against each other for the relative risk (RR) for inhospital mortality. In statistical testing, two-sided $P$ value less than 0.05 was considered statistically significant.

Table 1

RIFLE classification [24] for acute kidney injury

\begin{tabular}{lll}
\hline & GFR criteria & Urine output criteria \\
\hline Risk & Increase plasma creatinine $\times 1.5$ or GFR decrease $>25 \%$ & $<0.5 \mathrm{ml} / \mathrm{kg} / \mathrm{h} \times 6 \mathrm{~h}$ \\
Injury & Increase plasma creatinine $\times 2$ or GFR decrease $>50 \%$ & $<0.5 \mathrm{ml} / \mathrm{kg} / \mathrm{h} \times 12 \mathrm{~h}$ \\
Failure & $\begin{array}{l}\text { Increase plasma creatinine } \times 3 \text { or GFR decrease }>75 \% \text {, or serum creatinine } \geq 4 \mathrm{mg} / \mathrm{dL} \text { with an } \\
\text { acute rise }>0.5 \mathrm{mg} / \mathrm{dL}\end{array}$ & $<0.3 \mathrm{ml} / \mathrm{kg} / \mathrm{h} \times 24 \mathrm{~h}$ or anuria $\times 12 \mathrm{~h}$ \\
Loss & Persistent ARF $=$ complete loss of kidney function $>4 \mathrm{wk}$ & \\
ESRD & End-stage renal disease $(>3$ month)
\end{tabular}

ARF, acute renal failure; $E S R D=$ end stage renal disease; GFR $=$ glomerular filtration rate; $h=$ hours. 
Finally, Kaplan-Meier survival curves with log-rank test was drawn to express the differences of patient survival between the two groups (ED versus LD).

\section{Results}

Five hundred and ninety-six patients were screened. Patients on chronic dialysis $(n=165)$, those without surgery prior to RRT initiation ( $n=87$ ), or those whose surgery did not involve abdominal cavities $(n=244)$ were excluded. A 44-year-old male patient receiving kidney transplantation and an 85-yearold female patient with an extremely long hospital stay period (740 days from ICU admission to death, and 727 days from RRT initiation to death) were also excluded. Figure 1 shows the flowchart of patient gathering and selecting. Finally, a total of 98 patients (41 female, 57 male; mean age $66.4 \pm 13.9$ years) were selected and followed until 30 June, 2006. Of the 98 patients who underwent acute RRT following major abdominal surgery, most patients $(57.1 \%)$ underwent elective surgery. Surgery of the hepatobiliary organ was performed in 26 patients (26.5\%), upper Gl tract in 28 (28.6\%), lower GI tract in 29 (29.6\%), urological organs in 9 (9.2\%), and other sites in $6(6.1 \%)$. The surgery involving the hepatobiliary area included liver transplantation for hepatic failure $(n=14)$, hepa- tectomy or lobectomy for hepatoma ( $n=4)$, as well as cholecystectomy or choledocholithotomy owing to CBD stone ( $n=$ $3)$, acute or chronic cholecystitis $(n=4)$, and gall bladder adenocarcinoma $(n=1)$. The surgery involving upper Gl were gastrotomy, gastrectomy, or simple closure for peptic ulcer bleeding $(n=11)$, hallow organ perforation $(n=7)$, and malignancy $(n=4)$. Also, a Whipple operation for pancreatic cancer $(n=5)$ and chronic pancreastitis with obstructive jaundice ( $n$ $=1$ ) were also categorized as upper Gl surgery. The causes of lower Gl surgery were colon-rectal malignancy $(n=14)$, colon perforation $(n=5)$, exploratory laparotomy for appendicitis and colitis $(n=6)$, previous operation-related adhesion ( $n$ $=2)$, and ischemic bowel $(n=2)$. The surgery in urologic organs were nephrectomy, nephroureterectomy, and cystectomy related to malignancy $(n=9)$. Those included in the 'other sites' category were vein bypass for inferior vena cava occlusion $(n=1)$, abdominal aortic grafting $(n=1)$, repair of previous operation wound laceration $(n=1)$, and exploratory laparotomy for traffic accident $(n=1)$ and peritonitis $(n=2)$. The indications for RRT were 42 patients (42.9\%) started RRT due to azotemia with uremic symptoms, 40 (40.8\%) for oliguria, $10(10.2 \%)$ for fluid overload or pulmonary edema, and 14 $(14.3 \%)$ for hyperkalemia or acidosis. Because some patients

Figure 1

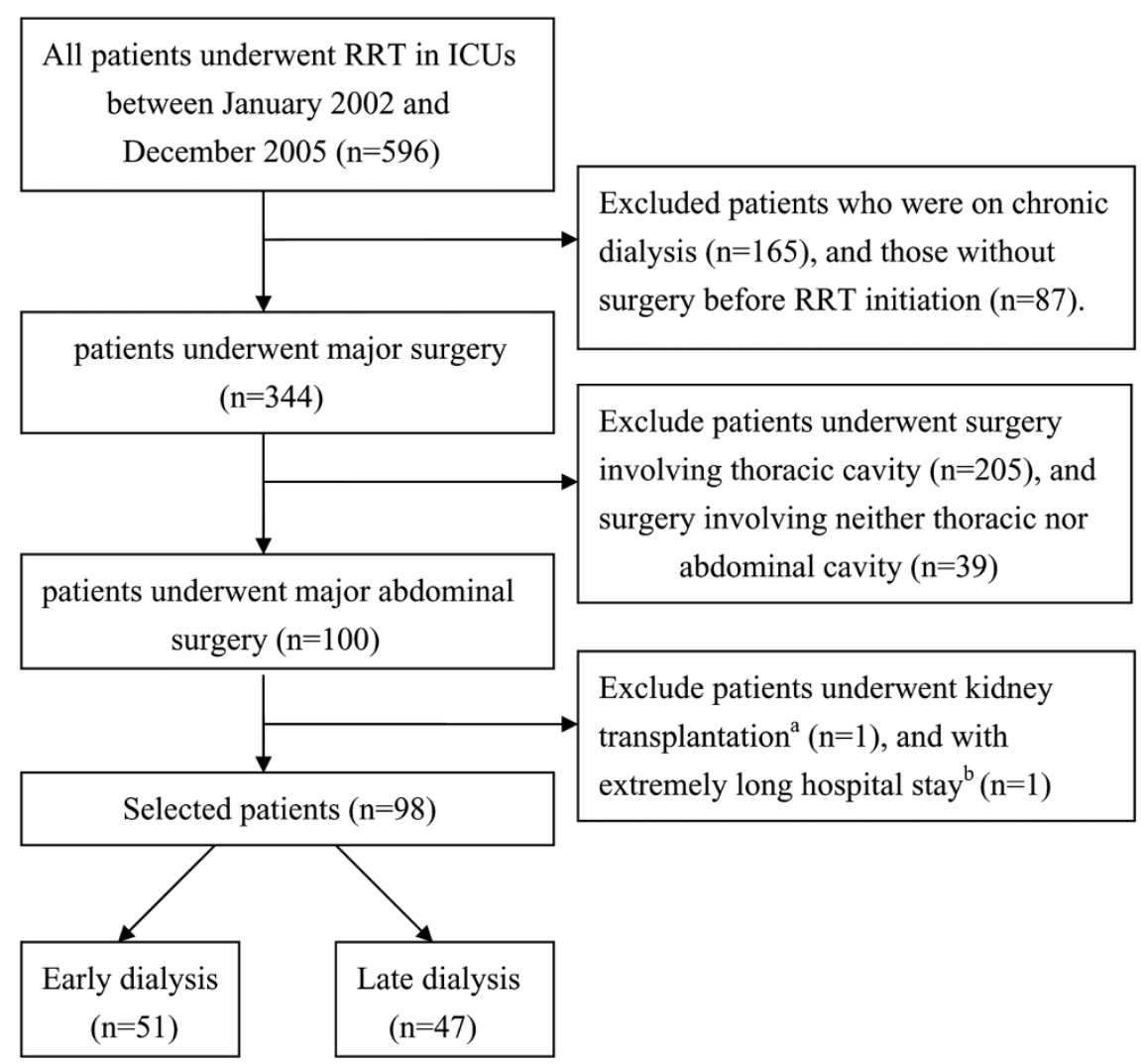

Approach to gathering and selecting patients. aA 44-year-old male received kidney transplantation prior to RRT. bA 85-year-old female whose hospital course is extremely long ( 727 days from RRT initiation to death, comparing to mean period of $34.3 \pm 27.6$ days in other 98 patients). ICU $=$ intensive care unit; RRT = renal replacement therapy. 
had more than one indication to start RRT, the sum of patient numbers were 106 instead of 98 patients.

Among the 98 patients, 51 patients $(52.0 \%$; 22 in sRIFLE-0 and 29 in sRIFLE-R) and 47 patients (48.0\%; 27 in sRIFLE-I and 20 in sRIFLE-F) were clarified as ED and LD groups, respectively. Fifty-three patients $(54.1 \%)$ died during ICU admission (21 (41.2\%) in ED group, 32 (68.1\%) in LD group), while a total of 57 patients $(58.2 \%)$ died during their whole hospital course $(22(43.1 \%)$ in ED group, $35(74.5 \%)$ in LD group). The LD group has a much lower prevalence of CKD (27.7\% versus $54.9 \%, P=0.008$ ), higher in-hospital mortality rate $(74.5 \%$ versus $43.1 \%, P=0.002)$ and borderline lower RRT wean-off rate $(21.3 \%$ versus $41.2 \%, P=0.050)$ as compared with the ED group. The baseline GFR ( $60.6 \pm 28.5$ versus $47.7 \pm 27.2, P=0.024)$ is higher, but baseline $\mathrm{sCr}(1.3 \pm$ 0.6 versus $2.1 \pm 1.7, P=0.003)$ and pre-RRT GFR (17.5 \pm 7.8 versus $32.8 \pm 50.3, P=0.036$ ) are lower in the LD group. The differences of other demographic, biochemistry data, severity scores, and usage of diuretics or vasopressors were not statistically significant (Table 2).

The statistically different demographic data between survivors and non-survivors were age $(P=0.014)$, cardiac failure $(P=$ $0.005)$, sepsis before RRT $(P=0.002)$, length of hospital stay $(P=0.025)$, and the period from ICU and RRT to death or discharge $(P=0.005$ and $<0.001$ respectively). GCS $(P=$ $0.040)$ and APACHE II scores $(P=0.010)$ at ICU admission, and pre-RRT platelet count $(P=0.027)$, BUN $(P=0.016)$, GCS $(P<0.001)$, APACHE $\|$ scores $(P<0.001)$, SOFA scores $(P=0.005)$, as well as the percentage of LD $(P=$ $0.002)$ and RRT wean-off rate $(P<0.001)$ were also statistically different. Other comorbid diseases, clinical parameters, and usage of diuretics or vasopressors were not statistically significant as compared between these two groups.

Using the backward stepwise likelihood ratio model of Cox proportional hazard method for in-hospital mortality, LD (hazard ratio (HR) 1.846; 95\% confidence interval (Cl) 1.0713.182; $P=0.027$ ), old age (older than 65 years) (HR 2.090; $95 \% \mathrm{Cl} 1.196-3.654, P=0.010$ ), cardiac failure (HR 4.620; 95\% Cl 2.216-9.632; $P<0.001$ ), and pre-RRT SOFA score (HR 1.152; 95\% Cl 1.065-1.247; $P<0.001$ ) were independent indicators for in-hospital mortality (Table 3 ). The predictive power for in-hospital mortality of LD (HR 1.756; 95\% Cl, 1.003-3.074; $P=0.049$ ) persisted in the additional Cox regression analysis in which the three variables (sepsis before RRT, mechanical ventilation, and diabetes) was forced into the analysis regardless of $P$ value. From the analysis comparing 'sRIFLE' categories against each other, we found a significant RR of 'sRIFLE-F' (RR 3.194, $P=0.014$ ), and a trend of increased risk of 'sRIFLE-I' (RR 2.121, $P=0.080$ ) as comparing with 'sRIFLE-R' (Table 4).
By Kaplan-Meier curves, we demonstrated that the survival proportion was much lower in LD group as compared with ED group $(P=0.022$; Figure 2$)$.

\section{Discussion RIFLE classification and RRT initiation}

The RIFLE classification [24] was proposed to standardize the severity of AKI, and it's predictive value for patient outcome was supported by many studies $[25,26,32]$. The stratification about the timing of RRT initiation by RIFLE classification has been recommended by the Acute Kidney Injury Network [33]. Our work is among the first few studies examining the relation between prognosis and timing of RRT initiation. We found that late initiation of RRT as defined by 'sRIFLE-l' and 'sRIFLE-F' is an independent predictor for in-hospital mortality in a relative homogenous group of patients with AKI after major abdominal surgery.

\section{Early versus late initiation of RRT}

Current practice suggests that RRT is indicated for a patient with an abruptly decreased renal function along with clinically significant solute imbalance or volume overload, yet there is no consensus on the definite indication for RRT in terms of any single metabolic or clinical parameters or RIFLE staging [33]. Although the benefit of early RRT initiation on survival outcome was revealed by a recent systemic review and meta-analysis [9], the question of 'how early is early enough?' is still unanswered because the early versus late RRT were defined by variable cutoff values of various metabolic parameters such as nitrogenous waste products, $\mathrm{sCr}, \mathrm{sK}^{+}$[34], urine amount, or even clinical judgment alone $[9,35]$. The present study defines the timing of RRT initiation by using RIFLE classification because this has been extensively validated to standardize the severity of AKI [33].

As it is reasonable that the patient survival is artificially extended if it is measured at an earlier time point with better residual renal function and less severity scores, and the socalled survival benefit from early RRT could be accounted for by lead-time bias [34]. However, the period from hospital admission to RRT initiation, as well as the severity scores including APACHE II score and SOFA score and almost all clinical parameters upon RRT initiation, which was taken as a starting point to calculate survival period, were of no statistical differences between ED and LD groups (Table 2). Therefore, the argument of lead-time bias would be minimized in the current study.

Two recent published studies $[27,28]$ have evaluated the association between the timing of RRT initiation by the RIFLE classification and outcome. Neither of them propose clearly defined indications for RRT. Only 33\% patients in one study [28] and none in the other [27] were categorized using both GFR and urine output criteria. The retrospective observational study by $\mathrm{Li}$ and colleagues [27] enrolled 106 critical AKI 
Critical Care Vol 13 No 5 Shiao et al.

Table 2

Comparisons of demographic data and clinical parameters between early and late dialysis groups $(n=98)$

\begin{tabular}{|c|c|c|c|}
\hline & Early dialysis $(n=51)$ & Late dialysis $(n=47)$ & $P$ value \\
\hline \multicolumn{4}{|l|}{ Demographic data } \\
\hline Female & $19(37.3)$ & $22(46.8)$ & 0.414 \\
\hline Diabetes & $14(27.5)$ & $17(36.2)$ & 0.391 \\
\hline Hypertension & $22(43.1)$ & $20(42.6)$ & 1.000 \\
\hline Cardiac failure & $6(11.8)$ & $4(8.5)$ & 0.743 \\
\hline Chronic kidney disease & $28(54.9)$ & $13(27.7)$ & 0.008 \\
\hline Sepsis before RRT & $14(27.5)$ & $17(36.2)$ & 0.391 \\
\hline Emergency surgery & $23(45.1)$ & $19(40.4)$ & 0.686 \\
\hline CVVH & $26(51.0)$ & $31(66.0)$ & 0.155 \\
\hline Mechanical ventilation & $39(76.5)$ & $40(85.1)$ & 0.316 \\
\hline Age (years) & $65.0 \pm 14.8$ & $68.0 \pm 13.0$ & 0.284 \\
\hline Old age ( $>65$ years) & $27(52.9)$ & $30(63.8)$ & 0.310 \\
\hline Hospital stay (days) & $53.7 \pm 39.2$ & $54.2 \pm 33.6$ & 0.944 \\
\hline Hospital admission to ICU (days) & $10.3 \pm 15.5$ & $12.6 \pm 13.0$ & 0.423 \\
\hline Hospital admission to RRT (days) & $17.5 \pm 20.3$ & $21.0 \pm 19.0$ & 0.388 \\
\hline ICU to RRT (days) & $7.3 \pm 13.2$ & $8.4 \pm 13.6$ & 0.679 \\
\hline $\mathrm{RRT}$ to death/discharge (days) & $35.5 \pm 29.0$ & $33.1 \pm 26.2$ & 0.671 \\
\hline Baseline creatinine (mg/dl) & $2.1 \pm 1.7$ & $1.3 \pm 0.6$ & 0.003 \\
\hline Baseline GFR $\left(\mathrm{ml} / \mathrm{min} / 1.73 \mathrm{~m}^{2}\right)$ & $47.7 \pm 27.2$ & $60.6 \pm 28.5$ & 0.024 \\
\hline Operation sites ${ }^{a}$ & & & 0.592 \\
\hline Hepatobiliary system & $13(25.5)$ & $13(27.7)$ & \\
\hline Upper Gl & $13(25.5)$ & 15 (31.9) & \\
\hline Lower Gl & $15(29.4)$ & $14(29.8)$ & \\
\hline Urologic system & $7(13.7)$ & $2(4.3)$ & \\
\hline Other sites & $3(5.9)$ & $3(6.4)$ & \\
\hline \multicolumn{4}{|l|}{ Data at ICU admission } \\
\hline Diuretics & $43(84.3)$ & $35(74.5)$ & 0.316 \\
\hline Vasopressors & $27(52.9)$ & $25(53.2)$ & 1.000 \\
\hline Inotropic equivalent & $7.80 \pm 12.63$ & $5.96 \pm 9.87$ & 0.426 \\
\hline Hematocrit (\%) & $29.3 \pm 7.3$ & $31.5 \pm 5.5$ & 0.105 \\
\hline BUN (mg/dl) & $50.9 \pm 33.0$ & $41.9 \pm 27.0$ & 0.143 \\
\hline Creatinine (mg/dl) & $2.9 \pm 1.9$ & $2.3 \pm 1.4$ & 0.137 \\
\hline GFR $\left(\mathrm{ml} / \mathrm{min} / 1.73 \mathrm{~m}^{2}\right)$ & $39.5 \pm 50.0$ & $38.6 \pm 26.7$ & 0.917 \\
\hline Albumin (g/dl) & $2.8 \pm 0.6$ & $2.6 \pm 0.7$ & 0.231 \\
\hline Potassium (mEq/l) & $4.2 \pm 0.7$ & $4.1 \pm 0.7$ & 0.552 \\
\hline $\mathrm{PaO}_{2} / \mathrm{FiO}_{2}$ & $281.1 \pm 112.1$ & $273.0 \pm 120.9$ & 0.732 \\
\hline GCS scores & $13.4 \pm 3.3$ & $12.6 \pm 3.8$ & 0.304 \\
\hline APACHE II scores & $18.2 \pm 5.4$ & $18.8 \pm 6.3$ & 0.620 \\
\hline SOFA scores & $8.3 \pm 2.7$ & $8.5 \pm 3.7$ & 0.767 \\
\hline
\end{tabular}




\begin{tabular}{|c|c|c|c|}
\hline \multicolumn{4}{|l|}{ Pre-RRT data } \\
\hline Hematocrit (\%) & $28.5 \pm 4.8$ & $29.4 \pm 5.0$ & 0.374 \\
\hline BUN (mg/dl) & $68.8 \pm 39.4$ & $81.9 \pm 39.3$ & 0.104 \\
\hline Creatinine (mg/dl) & $3.3 \pm 1.8$ & $3.8 \pm 1.3$ & 0.188 \\
\hline GFR $\left(\mathrm{ml} / \mathrm{min} / 1.73 \mathrm{~m}^{2}\right)$ & $32.8 \pm 50.3$ & $17.5 \pm 7.8$ & 0.036 \\
\hline Albumin (g/dl) & $2.8 \pm 0.6$ & $2.8 \pm 0.7$ & 0.722 \\
\hline Potassium (mEq/l) & $4.2 \pm 0.8$ & $4.3 \pm 0.7$ & 0.740 \\
\hline $\mathrm{PaO} 2 / \mathrm{FiO} 2$ & $300.3 \pm 112.1$ & $280.2 \pm 119.5$ & 0.395 \\
\hline GCS scores & $12.5 \pm 3.9$ & $11.3 \pm 4.5$ & 0.160 \\
\hline APACHE II scores & $18.2 \pm 6.1$ & $20.5 \pm 5.8$ & 0.061 \\
\hline SOFA scores & $9.4 \pm 3.1$ & $10.5 \pm 3.8$ & 0.114 \\
\hline \multicolumn{4}{|l|}{ Indications for RRT } \\
\hline Azotemia with uremic symptoms ${ }^{b}$ & $19(37.3)$ & $23(48.9)$ & 0.308 \\
\hline Oliguria or anuria ${ }^{c}$ & $23(45.1)$ & $17(36.2)$ & 0.415 \\
\hline Fluid overload or pulmonary edema ${ }^{d}$ & $4(7.8)$ & $6(12.8)$ & 0.513 \\
\hline Hyperkalemia or acidosise & $8(15.7)$ & $6(12.8)$ & 0.717 \\
\hline Hospital mortality & $22(43.1)$ & $35(74.5)$ & 0.002 \\
\hline RRT wean-off & $21(41.2)$ & $10(21.3)$ & 0.050 \\
\hline \multicolumn{4}{|c|}{ 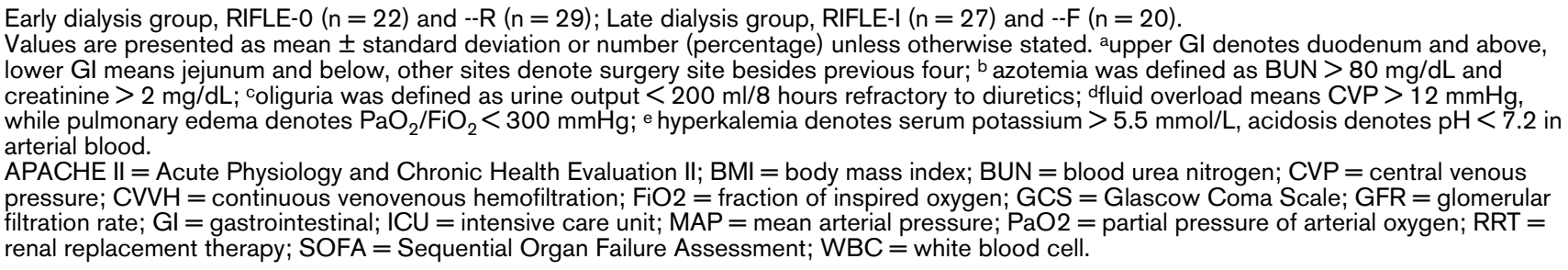 } \\
\hline
\end{tabular}

patients treated with continuous RRT. It found that the RIFLE classification may be used to predict 90-day survival after RRT initiation, and further analysis revealed that patient in RIFLE-F had a RR of 1.96 (95\% Cl: 1.06-3.62) comparing with those in RIFLE-R. The predictive effect was also seen in our work in which the RR of SRIFLE-F to sRIFLE-R was $3.194(P=0.014)$. As to the study of Maccariello and colleagues [28], a prospective cohort study including $214 \mathrm{AKI}$ patients who underwent

Table 3

Independent predictors for in-hospital mortality using Cox proportional hazards model

\begin{tabular}{|c|c|c|c|c|c|c|}
\hline \multirow[t]{2}{*}{ Variables } & \multicolumn{3}{|c|}{ Univariate } & \multicolumn{3}{|c|}{ Multivariate (Backward stepwise likelihood ratio) } \\
\hline & HR & $95 \% \mathrm{Cl}$ & $P$ & HR & $95 \% \mathrm{Cl}$ & $\boldsymbol{P}$ \\
\hline Old age $(>65 \text { years })^{a}$ & 1.960 & $1.127--3.408$ & 0.017 & 2.090 & $1.196--3.654$ & 0.010 \\
\hline Cardiac failure ${ }^{b}$ & 4.084 & 2.003--8.328 & $<0.001$ & 4.620 & $2.216--9.632$ & $<0.001$ \\
\hline Pre-RRT SOFA score ${ }^{c}$ & 1.138 & $1.054--1.228$ & 0.001 & 1.152 & 1.065--1.247 & $<0.001$ \\
\hline $\mathrm{CVVH}^{\mathrm{d}}$ & 1.940 & 1.123--3.352 & 0.018 & --- & $-\cdots$ & $-\cdots$ \\
\hline Late dialysis ${ }^{\mathrm{e}}$ & 1.852 & 1.081--3.170 & 0.025 & 1.846 & 1.071--3.182 & 0.027 \\
\hline
\end{tabular}

The independent variables were selected for multivariate analysis if they had a $P \leq 0.1$ on univariate analysis.

Data were gathered before RRT initiation. Duration in analysis is calculated from RRT initiation to end point (mortality or discharge).

a hazard for patients $>65$ years $=1.0 ;$ b hazard for patients without cardiac failure $=1.0 ;{ }^{c}$ every increment of 1 point; $d$ hazard for patients

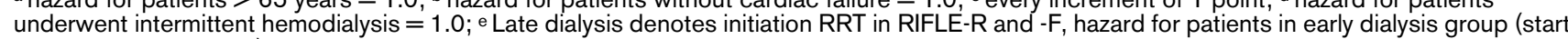
RRT in RIFLE-0 and - - I) $=1.0$.

APACHE II = Acute Physiology and Chronic Health Evaluation II; CVVH = continuous venovenous hemofiltration; $\mathrm{HR}=$ hazard ratio; $95 \% \mathrm{Cl}=$ 95\% confidence interval; RRT = renal replacement therapy; SOFA = Sequential Organ Failure Assessment. 
Table 4

Relative risk (RR) for in-hospital mortality using Cox proportional hazards model

\begin{tabular}{lllll}
\hline RIFLE categories & Patient number (\%) & RR $^{*}$ & $\mathbf{9 5 \%} \mathbf{C l}$ & \multicolumn{1}{c}{} \\
\hline RIFLE - R & $29(29.6)$ & 1.000 & Reference \\
RIFLE - I & $27(27.6)$ & 2.121 & $0.913-4.927$ & 0.080 \\
RIFLE - F & $20(20.4)$ & 3.194 & $1.262-8.085$ & 0.014 \\
\hline
\end{tabular}

* Adjusted for age ( $\geqq 65$ years vs $<65$ years), cardiac failure (with vs without), pre-RRT SOFA scores, and RRT modality (CVVH vs hemodialysis); $\mathrm{CVVH}=$ continuous venovenous hemofiltration; $95 \% \mathrm{Cl}=95 \%$ confidence interval; $\mathrm{RR}=$ relative risk; RRT = renal replacement therapy; SOFA = Sequential Organ Failure Assessment.

RRT, the RIFLE classification didn't show discrimination of prognosis in all patient populations. However, the association between RIFLE-F and increased in-hospital mortality was found while conducting a separate analysis study using only patients who underwent ventilation and vasopressors.

\section{Indications of RRT initiation}

In our study, RRT was provided to the patients according to the five criteria, namely, (1) azotemia with uremic symptoms, (2) oliguria or anuria, (3) fluid overload, (4) hyperkalemia, and (5) metabolic acidosis. Although the criteria for RRT were not too loose compared with those in other studies [9,33], about half of the patients who underwent RRT ( $n=51,52.0 \%$ ) were categorized into the ED group. This result was not surprising when compared with the largest study on the epidemiology of AKI during the entire ICU stay by Ostermann and Chang [30]. Among the total 1847 patients who underwent RRT in that

\section{Figure 2}

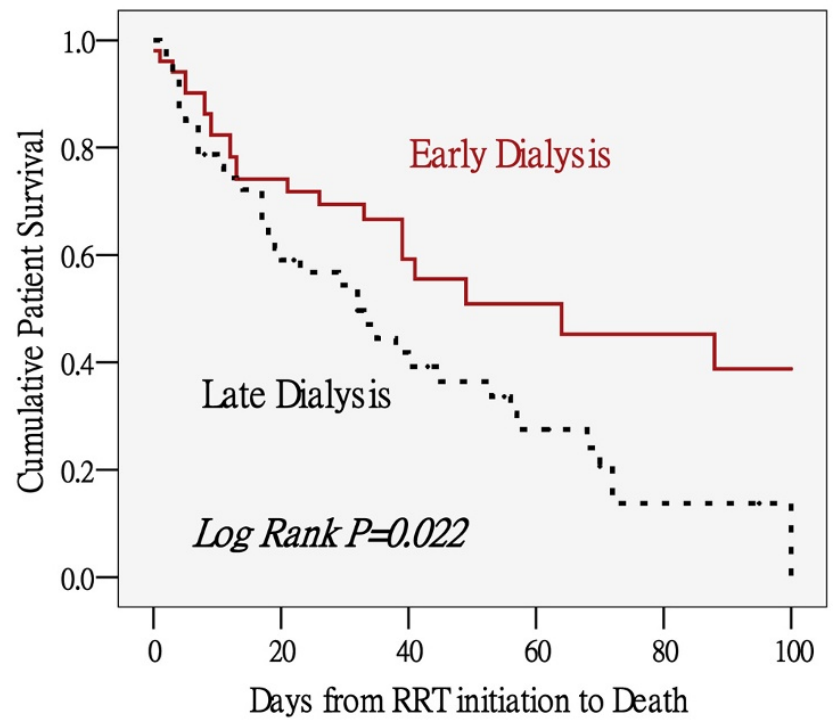

Cumulative patient survival between early and late dialysis groups defined by RIFLE classification. By Kaplan-Meier method. Brown solid line $=$ early dialysis group (RIFLE-O and $-I, n=51)$; black dashed line = late dialysis group (RIFLE-R and $-F, n=47$ ). RRT = renal replacement therapy. study, only 573 (31.0\%) fulfilled the sCr criterion and 691 (37.4\%) would probably fulfill the urine criterion for AKI stage III, and the remaining 583 (31.6\%) would be classified into earlier stage [36]. Actually, RIFLE classification and our own criteria for RRT are different scoring systems. The numbers of our indications for RRT are more than the parameters used in the RIFLE classification (only $\mathrm{sCr}$ level, GFR, and urine amount). Although the parameters in the RIFLE classification seems similar to the former two of our five RRT indications, the percentage change in $\mathrm{sCr}$ or GFR in RIFLE classification was different from the absolute BUN or $\mathrm{sCr}$ level in ours. Furthermore, 'oliguria or anuria' played a significant role as an indication for RRT in our study (45.1\% and 36.2\% in ED and LD, respectively) (Table 2), but the urine criterion of RIFLE classification was not used in categorizing patients. It means that those who met our study indications and received RRT accordingly may not be considered serious by RIFLE classification.

In critically ill patients, AKI is usually associated with multipleorgan failure. Preventing further renal damage and recovering renal function are largely dependent on recovery of other organ function. Thus, the concept has changed from 'renal replacement' to 'renal support' in ICU patients [37-39]. However, RRT has often been applied too late [40], leading to prolonged and poorly controlled uremia, restricted nutrition, acidosis, and volume overload [41]. In this study, the indications for RRT were not statistically different between ED and LD groups (Table 2), and survivors and non-survivors (detail not shown in the text). Thus, the survival benefit could not be simply explained by the causes of RRT initiation (such as fluid management or toxin removal), and the importance of early initiation of RRT clearly speaks for itself in this study [9].

\section{Predictors for in-hospital mortality}

More than half of patients who underwent RRT following major abdominal surgery died during hospital admission, which is comparable with previous studies $[29,42,43]$. Our study found that LD defined by sRIFLE classification, along with old age, cardiac failure, and pre-RRT SOFA scores, are strong predictors for in-hospital mortality. Old age has been a well-recognized predictor for mortality in critically ill surgical patients in 
many studies $[28,43,44]$. Cardiac failure is not only characterized by a high rate of hospital readmission and mortality in the general population [45], but is also considered an independent predictors for mortality in critically ill surgical patient with AKI [43]. Besides, SOFA score was chosen as a representation of severity score for Cox analysis in our study. The predictive value for poor prognosis in AKI of SOFA score has been reported in other studies $[1,30]$ as well.

Similar to the report of a systemic review and meta-analysis summarizing all studies published before 2008 [9], our data supported the survival benefit in earlier initiation of RRT. However, discordant results existed. Bagshaw and colleagues [46] designed a prospective multicenter observational study enrolling 1238 patients to evaluate the relation between timing of RRT initiation in severe AKI and prognoses. Timing of RRT was assessed by several approaches such as median value and median change of $\mathrm{BUN}$ and $\mathrm{sCr}$, and the period from ICU admission to start of RRT. Contrary to our findings, they found late RRT stratified by median $\mathrm{sCr}$ was associated with lower mortality. Previous studies [47] using sCr criterion to define early RRT also failed to show survival benefit. The main plausible explanation is that low $\mathrm{sCr}$ levels might not necessarily represent a better residual renal function. In contrast, the low $\mathrm{sCr}$ could be a marker of reduced muscle mass and malnutrition, and it may be a surrogate marker of volume overload, which in turn might contribute to poor survival $[33,46]$.

However, this bias did not exist in our study because the $\mathrm{sCr}$ and albumin level were not statistically different between ED and LD groups upon ICU admission and before RRT initiation (Table 2). In fact, the relation between $\mathrm{sCr}$ and mortality was ever documented to be paradoxical in dialysis patients, which is called 'reverse epidemiology'. It refers to paradoxical and counter-intuitive epidemiologic associations between survival outcomes and traditional risk factors such as creatinine [48].

It is worthy of mention that the LD group in our study has better baseline renal function (less CKD proportion, lower baseline $\mathrm{sCr}$, higher baseline GFR) but worse pre-RRT renal function. There is no doubt that a larger sCr increase or GFR decrease categorized patients into LD group, but it also gave a hint that those with more sever renal function deterioration have poorer outcome. Actually, both the proportional change of $\mathrm{sCr}$ or GFR in RIFLE classification, and the absolute sCr level in the SOFA scores could predict prognoses in our patients. This finding was supported by Coca and colleagues [49] who had disclosed the prognostic importance of a small acute change in $\mathrm{sCr}$ in absolute level as well as percentage changes.

\section{Limitations and summary}

Several limitations for this study should be recognized. First, the limited patient number may not be large enough to determine other risk factors for in-hospital mortality. Second, only GFR criterion of RIFLE classification was used in the current study. Although several studies $[29,30]$ did the same, it is a shortcoming to lack urine output when applying the RIFLE category. Thus we used the term 'sRIFLE' in our manuscript to distinguish from the original RIFLE. Therefore, observations accrued here might not be extrapolated to patients with AKI elsewhere. Further multicenter randomized clinical trials are warranted to confirm our findings.

\section{Conclusions}

LD defined by RIFLE-I or RIFLE-F of 'simplified' RIFLE classification is an independent predictor for in-hospital mortality in the current study. Our findings support earlier initiation of RRT, and also underscore the importance of predicting prognoses of patients with AKI by using RIFLE classification.

\section{Key messages}

- $\quad \mathrm{AKI}$ is a common problem in critically ill patients, and postoperative $\mathrm{AKI}$ is one of the most serious complications in surgical patients.

- The RIFLE classification was proposed to standardize AKI study, and it's predictive value for patient outcome was supported by many studies.

- Late initiation of RRT defined by RIFLE-I or RIFLE-F is an independent predictor for in-hospital mortality in the current study. Our findings support early initiation of $\mathrm{RRT}$, and also underscore the importance of predicting prognoses of patients with AKI by using RIFLE classification.

\section{Competing interests}

The authors declare that they have no competing interests.

\section{Authors' contributions}

CCS, VCW, and CCK have made substantial contributions to conception and design, and drafted the manuscript. WYL, $\mathrm{DMH}, \mathrm{SLL}$ and PRT were involved in acquisition and interpretation of data. YFL, GHY, and $\mathrm{CHW}$ participated in the sequence alignment and drafted the manuscript. $\mathrm{FCH}, \mathrm{NKC}$, and THL participated in the design of the study and performed the statistical analysis. TWK, YCY, and YMC participated in its design and coordination and helped to draft the manuscript. MTL, AC, WJK, and KDW revised the manuscript critically for important intellectual content, and have given final approval of the version to be published. All authors read and approved the final manuscript

\section{Acknowledgements}

This study was financially supported by the Improving Dialysis Quality Research Funds, Ta-Tung Kidney Foundation, and Taiwan National Science Council (grant NSC 98-2314-B-002-108-MY2). The National Taiwan University Surgical ICU Associated Renal Failure (NSARF) Study Group including Yu-Feng Lin, MD, Vin-Cent Wu, MD, Wen-Je Ko, MD, $\mathrm{PhD}$, Yih-Sharng Chen, MD, PhD, Nai-Kuan Chou, MD, PhD, Anne Chou, MD, Yen-Hung Lin, MD, Chih-Chung Shiao, MD, Wen- Yi Li, MD, Down-Ming Huang, MD, Fan-Chi Chang, MD, Chin-Chi Kuo, MD, Chin- 
Wei Tsai, MD, Cheng-Yi Wang, MD, Yung-Wei Chen, MD, Yung-Ming Chen, MD, Pi-Ru Tsai, RN, Hung-Bin Tsai, MD, Tzong-Yann Lee, MD, Jann-Yuan Wang, MD, Fu-Chang Hu, MS, ScD, and Kwan-Dun Wu, MD, $\mathrm{PhD}$.

\section{References}

1. de Mendonca A, Vincent JL, Suter PM, Moreno R, Dearden NM, Antonelli M, Takala J, Sprung C, Cantraine F: Acute renal failure in the ICU: risk factors and outcome evaluated by the SOFA score. Intensive Care Med 2000, 26:915-921.

2. Kellum JA, Bellomo R, Ronco C: Definition and classification of acute kidney injury. Nephron Clin Pract 2008, 109:c182-187.

3. Brienza N, Giglio MT, Marucci M, Fiore T: Does perioperative hemodynamic optimization protect renal function in surgical patients? A meta-analytic study. Crit Care Med 2009, 37:2079-2090.

4. Kheterpal S, Tremper KK, Englesbe MJ, O'Reilly M, Shanks AM, Fetterman DM, Rosenberg AL, Swartz RD: Predictors of postoperative acute renal failure after noncardiac surgery in patients with previously normal renal function. Anesthesiology 2007, 107:892-902.

5. Sear JW: Kidney dysfunction in the postoperative period. $\mathrm{Br} \mathrm{J}$ Anaesth 2005, 95:20-32.

6. Burns KE, Chu MW, Novick RJ, Fox SA, Gallo K, Martin CM, Stitt LW, Heidenheim AP, Myers ML, Moist L: Perioperative N-acetylcysteine to prevent renal dysfunction in high-risk patients undergoing cabg surgery: a randomized controlled trial. JAMA 2005, 294:342-350.

7. McNelis J, Soffer S, Marini CP, Jurkiewicz A, Ritter G, Simms HH, Nathan I: Abdominal compartment syndrome in the surgical intensive care unit. Am Surg 2002, 68:18-23.

8. Traynor JP, Simpson K, Geddes CC, Deighan CJ, Fox JG: Early initiation of dialysis fails to prolong survival in patients with end-stage renal failure. $J A m$ Soc Nephrol 2002, 13:2125-2132.

9. Seabra VF, Balk EM, Liangos O, Sosa MA, Cendoroglo M, Jaber $\mathrm{BL}$ : Timing of renal replacement therapy initiation in acute renal failure: a meta-analysis. Am J Kidney Dis 2008, 52:272-284.

10. Clark WR, Letteri JJ, Uchino S, Bellomo R, Ronco C: Recent Clinical Advances in the Management of Critically III Patients with Acute Renal Failure. Blood Purif 2006, 24:487-498.

11. Kellum JA, Levin N, Bouman C, Lameire N: Developing a consensus classification system for acute renal failure. Curr Opin Crit Care 2002, 8:509-514.

12. Bouman CS, Oudemans-Van Straaten HM, Tijssen JG, Zandstra $D F$, Kesecioglu J: Effects of early high-volume continuous venovenous hemofiltration on survival and recovery of renal function in intensive care patients with acute renal failure: a prospective, randomized trial. Crit Care Med 2002, 30:2205-2211.

13. Lin YF, Ko WJ, Wu VC, Chen YS, Chen YM, Hu FC, Shiao CC, Wu MS, Chen YW, Li WY, Huang TM, Wu KD, Chu TS: A modified sequential organ failure assessment score to predict hospital mortality of postoperative acute renal failure patients requiring renal replacement therapy. Blood Purif 2008, 26:547-554.

14. Wu VC, Wang CH, Wang WJ, Lin YF, Hu FC, Chen YW, Chen YS, Wu MS, Lin YH, Kuo CC, Huang TM, Chen YM, Tsai PR, Ko WJ, Wu KD: Sustained low-efficiency dialysis versus continuous veno-venous hemofiltration for postsurgical acute renal failure. Am J Surg 2009 in press.

15. Wu VC, Ko WJ, Chang HW, Chen YW, Lin YF, Shiao CC, Chen YM, Chen YS, Tsai PR, Hu FC, Wang JY, Lin YH, Wu KD: Risk factors of early redialysis after weaning from postoperative acute renal replacement therapy. Intensive Care Med 2008, 34:101-108.

16. Lindenauer PK, Pekow P, Wang K, Mamidi DK, Gutierrez B, Benjamin EM: Perioperative beta-blocker therapy and mortality after major noncardiac surgery. N Engl J Med 2005, 353:349-361.

17. Lee TH, Marcantonio ER, Mangione CM, Thomas EJ, Polanczyk CA, Cook EF, Sugarbaker DJ, Donaldson MC, Poss R, Ho KK, Ludwig LE, Pedan A, Goldman L: Derivation and prospective validation of a simple index for prediction of cardiac risk of major noncardiac surgery. Circulation 1999, 100:1043-1049.
18. Wu VC, Ko WJ, Chang HW, Chen YS, Chen YW, Chen YM, Hu $\mathrm{FC}$, Lin YH, Tsai PR, Wu KD: Early renal replacement therapy in patients with postoperative acute liver failure associated with acute renal failure: effect on postoperative outcomes. J Am Coll Surg 2007, 205:266-276.

19. Knaus WA, Draper EA, Wagner DP, Zimmerman JE: APACHE II: a severity of disease classification system. Crit Care Med 1985, 13:818-829.

20. Vincent JL, Moreno R, Takala J, Willatts S, De Mendonca A, Bruining $\mathrm{H}$, Reinhart CK, Suter PM, Thijs LG: The SOFA (Sepsisrelated Organ Failure Assessment) score to describe organ dysfunction/failure. On behalf of the Working Group on Sepsis-Related Problems of the European Society of Intensive Care Medicine. Intensive Care Med 1996, 22:707-710.

21. Chen YS, Ko WJ, Lin FY, Huang SC, Chou TF, Chou NK, Hsu RB, Wang SS, Chu SH: Preliminary result of an algorithm to select proper ventricular assist devices for high-risk patients with extracorporeal membrane oxygenation support. J Heart Lung Transplant 2001, 20:850-857.

22. Lin YH, Pao KY, Wu VC, Lin YL, Chien YF, Hung CS, Chen YJ, Liu CP, Tsai IJ, Gau CS, Wu KD, Hwang JJ: The influence of estimated creatinine clearance on plasma homocysteine in hypertensive patients with normal serum creatinine. Clin Biochem 2007, 40:230-234.

23. Wu VC, Wang YT, Wang CY, Tsai IJ, Wu KD, Hwang JJ, Hsueh PR: High frequency of linezolid-associated thrombocytopenia and anemia among patients with end-stage renal disease. Clin Infect Dis 2006, 42:66-72.

24. Bellomo R, Ronco C, Kellum JA, Mehta RL, Palevsky P: Acute renal failure - definition, outcome measures, animal models, fluid therapy and information technology needs: the Second International Consensus Conference of the Acute Dialysis Quality Initiative (ADQI) Group. Crit Care 2004, 8:R204-212.

25. Lin CY, Chen YC, Tsai FC, Tian YC, Jenq CC, Fang JT, Yang CW: RIFLE classification is predictive of short-term prognosis in critically ill patients with acute renal failure supported by extracorporeal membrane oxygenation. Nephrol Dial Transplant 2006, 21:2867-2873.

26. Kuitunen $A$, Vento $A$, Suojaranta-Ylinen R, Pettila V: Acute renal failure after cardiac surgery: evaluation of the RIFLE classification. Ann Thorac Surg 2006, 81:542-546.

27. Li WX, Chen HD, Wang XW, Zhao S, Chen XK, Zheng Y, Song Y: Predictive value of RIFLE classification on prognosis of critically ill patients with acute kidney injury treated with continuous renal replacement therapy. Chin Med J (Engl) 2009, 122:1020-1025.

28. Maccariello E, Soares M, Valente C, Nogueira L, Valenca RV, Machado JE, Rocha E: RIFLE classification in patients with acute kidney injury in need of renal replacement therapy. Intensive Care Med 2007, 33:597-605.

29. Uchino S, Bellomo R, Goldsmith D, Bates S, Ronco C: An assessment of the RIFLE criteria for acute renal failure in hospitalized patients. Crit Care Med 2006, 34:1913-1917.

30. Ostermann M, Chang R: Correlation between the AKI classification and outcome. Crit Care 2008, 12:R144.

31. K/DOQI clinical practice guidelines for chronic kidney disease evaluation, classification, and stratification. Am J Kidney Dis 2002, 39:S1-266.

32. Ahlstrom A, Kuitunen A, Peltonen S, Hynninen M, Tallgren M, Aaltonen J, Pettila V: Comparison of 2 acute renal failure severity scores to general scoring systems in the critically ill. $\mathrm{Am} \mathrm{J} \mathrm{Kid-}$ ney Dis 2006, 48:262-268.

33. Gibney N, Hoste E, Burdmann EA, Bunchman T, Kher V, Viswanathan R, Mehta RL, Ronco C: Timing of initiation and discontinuation of renal replacement therapy in AKI: unanswered key questions. Clin J Am Soc Nephrol 2008, 3:876-880.

34. Korevaar JC, Jansen MA, Dekker FW, Jager KJ, Boeschoten EW, Krediet RT, Bossuyt PM: When to initiate dialysis: effect of proposed US guidelines on survival. Lancet 2001, 358:1046-1050.

35. Pursnani ML, Hazra DK, Singh B, Pandey DN: Early haemodialysis in acute tubular necrosis. J Assoc Physicians India 1997, 45:850-852.

36. Mehta RL, Kellum JA, Shah SV, Molitoris BA, Ronco C, Warnock DG, Levin A: Acute Kidney Injury Network: report of an initiative to improve outcomes in acute kidney injury. Crit Care 2007, 11:R31. 
37. Parikh CR, Garg AX: Acute kidney injury: Better biomarkers and beyond. Kidney Int 2008, 73:801-803.

38. Demirkilic U, Kuralay E, Yenicesu M, Caglar K, Oz BS, Cingoz F, Gunay C, Yildirim V, Ceylan S, Arslan M, Vural A, Tatar H: Timing of replacement therapy for acute renal failure after cardiac surgery. J Card Surg 2004, 19:17-20.

39. Palevsky PM: Clinical review: timing and dose of continuous renal replacement therapy in acute kidney injury. Crit Care 2007, 11:232.

40. Baudouin SV, Wiggins J, Keogh BF, Morgan CJ, Evans TW: Continuous veno-venous haemofiltration following cardio-pulmonary bypass. Indications and outcome in $\mathbf{3 5}$ patients. Intensive Care Med 1993, 19:290-293.

41. Bent P, Tan HK, Bellomo R, Buckmaster J, Doolan L, Hart G, Silvester W, Gutteridge G, Matalanis G, Raman J, Rosalion A, Buxton BF: Early and intensive continuous hemofiltration for severe renal failure after cardiac surgery. Ann Thorac Surg 2001, 71:832-837.

42. Metnitz PG, Krenn CG, Steltzer H, Lang T, Ploder J, Lenz K, Le Gall $J R$, Druml W: Effect of acute renal failure requiring renal replacement therapy on outcome in critically ill patients. Crit Care Med 2002, 30:2051-2058.

43. Eachempati SR, Wang JC, Hydo LJ, Shou J, Barie PS: Acute renal failure in critically ill surgical patients: persistent lethality despite new modes of renal replacement therapy. I Trauma 2007, 63:987-993.

44. Fertmann J, Wolf $\mathrm{H}$, Kuchenhoff $\mathrm{H}$, Hofner B, Jauch KW, Hartl WH: Prognostic factors in critically ill surgical patients requiring continuous renal replacement therapy. J Nephrol 2008, 21:909-918.

45. Gwadry-Sridhar FH, Flintoft V, Lee DS, Lee H, Guyatt GH: A systematic review and meta-analysis of studies comparing readmission rates and mortality rates in patients with heart failure. Arch Intern Med 2004, 164:2315-2320.

46. Bagshaw SM, Uchino S, Bellomo R, Morimatsu H, Morgera S, Schetz M, Tan I, Bouman C, Macedo E, Gibney N, Tolwani A, Oudemans-van Straaten HM, Ronco C, Kellum JA: Timing of renal replacement therapy and clinical outcomes in critically ill patients with severe acute kidney injury. J Crit Care 2009, 24:129-140.

47. Beddhu S, Samore MH, Roberts MS, Stoddard GJ, Ramkumar N, Pappas LM, Cheung AK: Impact of timing of initiation of dialysis on mortality. J Am Soc Nephro/ 2003, 14:2305-2312.

48. Horwich TB, Fonarow GC: Reverse epidemiology beyond dialysis patients: chronic heart failure, geriatrics, rheumatoid arthritis, COPD, and AIDS. Semin Dial 2007, 20:549-553.

49. Coca SG, Peixoto AJ, Garg AX, Krumholz HM, Parikh CR: The prognostic importance of a small acute decrement in kidney function in hospitalized patients: a systematic review and meta-analysis. Am J Kidney Dis 2007, 50:712-720. 